Network Working Group

Request for Comments: 2838

Category: Informational
D. Zigmond WebTV Networks, Inc.

M. Vickers Liberate Technologies, Inc.

May 2000

\title{
Uniform Resource Identifiers for Television Broadcasts
}

Status of this Memo

This memo provides information for the Internet community. It does not specify an Internet standard of any kind. Distribution of this memo is unlimited.

Copyright Notice

Copyright (C) The Internet Society (2000). All Rights Reserved.

1. Introduction

World-Wide Web browsers are starting to appear on a variety of consumer electronic devices, such as television sets and television set-top boxes, which are capable of receiving television programming from either terrestrial broadcast, satellite broadcast, or cable. In this context there is a need to reference television broadcasts using the URI format described in [RFC 2396]. This document describes a widely-implemented URI scheme to refer to such broadcasts.

2. Television URI

The basic structure of a television URI is:

tv $:\langle$ broadcast $>$

where broadcast is a description of the data source. The description takes the form of a DNS-style identifier for a particular broadcaster or television network. For example:

tv:wqed.org

tv $: \mathrm{nbc} . \mathrm{com}$ the WQED station

the NBC network 
3.1. Scheme-only form

A simplest form of the "tv:" URI scheme is used to refer to the "current" or "default" channel:

tv:

This URI refers to whichever television broadcast is currently being received by the device. It is often used in combination with HTML content that is actually being broadcast along with the audio and video, where the meaning of "current broadcast" is quite unambiguous (because it is the broadcast along with which the content containing the URI was received). This is in fact the most common usage of the "tv:" scheme today, and is explicitly referenced by the recently published specification of the Advanced Television Enhancement Forum [ATVEF 1.1].

\subsection{DNS-style identifiers}

Television broadcasts traditionally have been identified in a variety of ways. All terrestrial television broadcasters are assigned call signs (such as "KDKA" or "WQED") to identify their signal. These are generally assigned by national authorities (such as the Federal Communications Commission in the United States) and are world unique. The global namespace is managed by the International

Telecommunications Union, which assigns portions to member countries (see [ITU RR]).

Many modern television networks are not broadcasted over-the-air, but available only through cable or satellite subscriptions. The identifiers for these networks (such as the familiar "CNN" and "HBO") are not regulated at this time. In some countries, even over-the-air broadcasters use these sorts of identifiers, rather than call signs.

Unfortunately, these two namespaces overlap, with most network identifiers also being valid call signs. Furthermore, network identifiers are not world unique, and many cases exist of name collisions. (For example, both the Australian Broadcast Corporation and the American Broadcasting Company identify themselves as "ABC".) In order to ensure uniqueness, the "tv:" scheme uses DNS-style identifiers for all broadcast streams. Because these build on the existing registration system for DNS hostname, all name collisions can be resolved through the existing DNS dispute resolution processes. 
In the simplest form, domain names themselves are used as broadcast identifiers. For example:
tv: abc.com
the American Broadcast Company
tv:abc.co.au
the Australian Broadcast Corporation

In some cases, networks have multiple broadcast streams that need to be distinguished. This is also handled in DNS style:

$$
\begin{array}{ll}
\text { tv:east.hbo.com } & \text { HBO East } \\
\text { tv:west.hbo.com } & \text { HBO West }
\end{array}
$$

It is important to note that these DNS-style identifiers need not match real hostnames; they should not be resolved to IP addresses using DNS. Thus, using the terms as defined in RFC 2396, the "tv:" scheme is a Uniform Resource Identifier and not a Uniform Resource Locator.

In order to support these identifiers in a "tv:" URI, a receiver must implement a means to map known identifiers to frequencies. The nature of this map and the way in which it is used are currently browserand device-specific and are beyond the scope of this document. In this way, the "tv:" scheme is somewhat analogous to the "news:" and "file:" schemes in [1]: it merely names a television broadcast signal but assumes that the local browser has some means for actually retrieving that signal on the local device. A variety of software systems currently provide device-specific mappings from such identifiers to specific channel numbers or directly to frequencies. These systems can be incorporated into television sets or set-top boxes to facilitate the interpretation of television URIs by the client device.

\subsection{Obsolete forms}

Previous drafts of this specification allowed broadcasts to be identified by channel numbers, such as "tv:4", and this form is currently supported by several independent platforms. The channel numbers generally correspond to tuning frequencies in the various national broadcast frequency standards; for example, "tv:4" in the United states would be found at $66 \mathrm{MHz}$. However, because this mapping of channel numbers to frequencies varies from country to country, this form is particularly ill-suited to use on the Internet.

Previous drafts also allowed network identifiers and call signs to be used directly as broadcast identifiers, as in "tv:abc" and "tv:kron". These forms should not be used because of the name collision issues described in the previous section. 
4. BNF for Television URIs

The following is a formal specification for the new URIs:

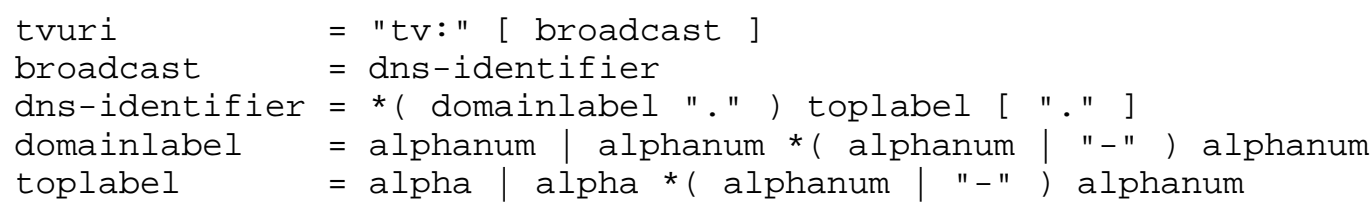

The definitions of alpha and alphanum are from [RFC 2396]. Furthermore, the definition of dns-identifier is identical to the definition of hostname in RFC 2396, and is case-insensitive.

5. Acknowledgments

Many of the ideas in this document came out of conversations with Andrew Lochart. Other people who supplied valuable input include Matt Trifiro and Eric Del Sesto. The original draft of this URI scheme was developed while the author was at Wink Communications. More recent suggestions have come from Lee Acton, Jonathan Boltax, Dean Blackketter, Michael Dolan, Iain Hackett, Jim Helman, Sean McDowell, David Mott, Scott Watson, and others in the ATVEF Technical Working Group (which the authors co-chaired), and from Craig Finseth, Gomer Thomas, Harald Alvestrand, and Larry Masinter.

6. Security Considerations

This new URI scheme is subject to the same security implications as the general URI scheme described in [RFC 2396]. It is possible that the mere act of viewing a television broadcast signal may cause costs to be incurred to the viewer in some instances (e.g., "pay-per-view" movies and events). Any software that uses this URI scheme to allow automatic tuning of a client device to a particular television broadcast signal should alert users before performing actions that may incur costs to the user.

7. References

[RFC 2396] Berners T., Fielding, R. and L. Masinter, "Uniform Resource Identifiers (URI): Generic Syntax", RFC 2396, August 1998 .

[ATVEF 1.1] Advanced Television Enhancement Forum, "Advanced Television Enhancement Forum Specification Version 1.1r26," February 1999. http://www.atvef.com/library/spec1_la.html 
[ITU RR] International Telecommunications Union, "Radio Regulations," 1998. See especially Article S19, "Identification of stations," and Appendix S42, "Table of allocation of international call sign series."

9. Authors' Addresses

Dan Zigmond

WebTV Networks, Inc.

1065 La Avenida

Mountain View, CA 94043

USA

EMail: djz@corp.webtv. net

Mark Vickers

Liberate Technologies

2 Circle Star Way

San Carlos, CA 94070

USA

EMail: maveliberate.com 
10. Full Copyright statement

Copyright (C) The Internet Society (2000). All Rights Reserved.

This document and translations of it may be copied and furnished to others, and derivative works that comment on or otherwise explain it or assist in its implementation may be prepared, copied, published and distributed, in whole or in part, without restriction of any kind, provided that the above copyright notice and this paragraph are included on all such copies and derivative works. However, this document itself may not be modified in any way, such as by removing the copyright notice or references to the Internet society or other Internet organizations, except as needed for the purpose of developing Internet standards in which case the procedures for copyrights defined in the Internet Standards process must be followed, or as required to translate it into languages other than English.

The limited permissions granted above are perpetual and will not be revoked by the Internet society or its successors or assigns.

This document and the information contained herein is provided on an "AS IS" basis and THE INTERNET SOCIETY AND THE INTERNET ENGINEERING TASK FORCE DISCLAIMS ALL WARRANTIES, EXPRESS OR IMPLIED, INCLUDING BUT NOT LIMITED TO ANY WARRANTY THAT THE USE OF THE INFORMATION HEREIN WILL NOT INFRINGE ANY RIGHTS OR ANY IMPLIED WARRANTIES OF MERCHANTABILITY OR FITNESS FOR A PARTICULAR PURPOSE.

Acknowledgement

Funding for the RFC Editor function is currently provided by the Internet society. 